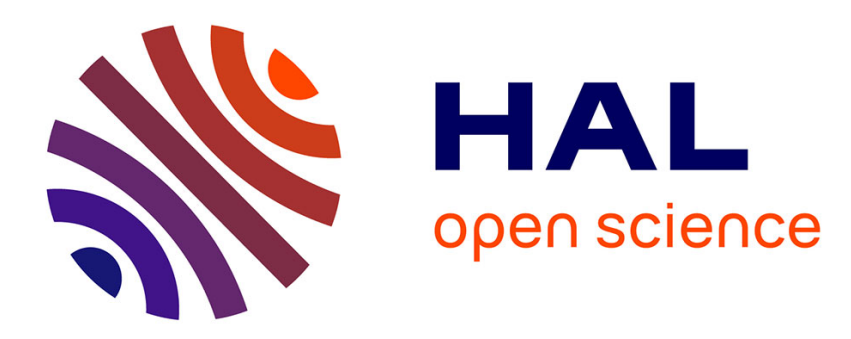

\title{
The Portfolio Rebalancing Channel of Quantitative Easing
}

Valentin Jouvanceau

\section{To cite this version:}

Valentin Jouvanceau. The Portfolio Rebalancing Channel of Quantitative Easing. 2016. halshs01349870

\section{HAL Id: halshs-01349870 \\ https://shs.hal.science/halshs-01349870}

Preprint submitted on 29 Jul 2016

HAL is a multi-disciplinary open access archive for the deposit and dissemination of scientific research documents, whether they are published or not. The documents may come from teaching and research institutions in France or abroad, or from public or private research centers.
L'archive ouverte pluridisciplinaire HAL, est destinée au dépôt et à la diffusion de documents scientifiques de niveau recherche, publiés ou non, émanant des établissements d'enseignement et de recherche français ou étrangers, des laboratoires publics ou privés. 
UMR 5824

93. chemin des Mouilles 69130 Ecully - France

Maison de IUniversité, Bâtiment 10, rue Trefilerie 42023 Saint-Etienne cedex $02 \cdot$ France http://www.gate.cnis.fr gate@gate.cnrs.fr

WP 1625 - July 2016

\title{
The Portfolio Rebalancing Channel of Quantitative Easing
}

\author{
Valentin Jouvanceau
}

\begin{abstract}
:
This paper analyzes the portfolio rebalancing channel of Quantitative Easing (QE hereafter) interventions. First, we identify the effects of a QE shock using a Bayesian VAR on US data using a sign and zero restrictions identification scheme. We find that QE shocks have substantial effects on corporate spreads with different ratings, supportive of a portfolio rebalancing channel. Second, we build a DSGE model with a securitzation mechanism. We confront the resulting impulse response functions to those uncovered by our VAR analysis, and find a fairly good match. Finally, we show that the portfolio rebalancing channel crucially affects the transmission of $Q E$ shocks to real economy.
\end{abstract}

\section{Keywords:}

Quantitative easing, securitization, financial intermediation, portfolio rebalancing channel.

JEL codes:

E44, E52, G2

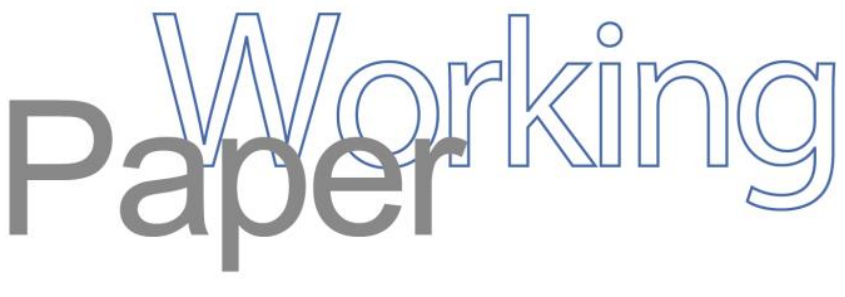




\title{
The Portfolio Rebalancing Channel of Quantitative Easing*
}

\author{
Valentin Jouvanceau ${ }^{\dagger}$
}

July, 2016

\begin{abstract}
This paper analyzes the portfolio rebalancing channel of Quantitative Easing (QE hereafter) interventions. First, we identify the effects of a QE shock using a Bayesian VAR on US data using a sign and zero restrictions identification scheme. We find that QE shocks have substantial effects on corporate spreads with different ratings, supportive of a portfolio rebalancing channel. Second, we build a DSGE model with a securitzation mechanism. We confront the resulting impulse response functions to those uncovered by our VAR analysis, and find a fairly good match. Finally, we show that the portfolio rebalancing channel crucially affects the transmission of QE shocks to real economy.
\end{abstract}

Keywords: Quantitative easing, securitization, financial intermediation, portfolio rebalancing channel.

JEL Classification.: E44, E52, G2.

${ }^{*}$ All errors and omissions are my own.

†Univ Lyon, Université Lumière Lyon 2, GATE L-SE UMR 5824, F-69130, Ecully, France; e-mail: jouvanceau@gate.cnrs.fr 


\section{Introduction}

QE consists in an increase in the asset side of the balance sheet of a central bank aimed at lowering interest rates (sovereign or corporate) at longer maturities than achieved with conventional policy rates (Federal funds rates). The transmission channels of such interventions are usually the signaling channel, the liquidity premium channel, the credit channel, the fiscal channel and the portfolio rebalancing channel. More precisely, QE interventions aim at reducing risk premia and returns on long term securities and bonds. The portfolio rebalancing channel is then thought to boost economic activity by spreading over yields on other assets. Indeed, changes in relative yields of purchased assets cause investors to shift their holdings towards close substitutes searching for higher perspective of returns. This tends to spread the shock along the yield curve through an increase in the price of long-term assets and bonds held by financial intermediaries, which also generates a wealth effect. In addition, purchases of long-term securities or bonds affect financial conditions by reducing borrowing costs. Both effects are mutually reinforced to provide further stimulus to the economy.

This paper analyzes both empirically and theoretically the portfolio rebalancing channel of QE interventions. We build a Bayesian VAR model using US data based on an extension of the algorithm of Rubio-Ramírez et al. (2010) developed by Binning (2013). Identification is achieved with sign and zero restrictions and our results support the presence of a portfolio rebalancing channel or at the very least, behavioral assumptions made about financial intermediaries on which the portfolio rebalancing channel is based. We then design a DSGE model à la Gertler \& Karadi (2013) (GKb) augmented with Special Purpose Entities in the spirit of Meeks et al. (2014). In addition, we consider an additional housing market à la Iacoviello \& Neri (2008), in which Government-Sponsored Enterprises issue Mortgage Backed Securities (MBS). Doing so provides an additional transmission mechanism of the QE policies. What is crucial in our approach is that we introduce a variety of assets and bonds that are close substitutes but whose prices may be altered differently by QE shocks, thereby making room for potential portfolio reallocations.

First, we proceed to the empirical analysis of an identified QE shock on US data and find sizable effects to the real economy. Moreover, our analysis uncovers statistically significant negative responses of corporate spreads after a $\mathrm{QE}$ shock. In particular, the response of a spread between private assets that are close substitutes (BAA and AAA rated bonds)

is significant and negative, suggesting that investors should rebalance their portfolios in the wake of a QE shock. Our results thus point to the presence of a portfolio rebalancing 
channel in the data. Second, we build a theoretical model and calibrate it to the US precrisis period in line with GKb. We then successfully compare the impulse response functions (IRFs) of both models to comfort the qualitative and quantitative strengths of our DSGE model. We thus consider our theoretical model as a suitable framework to identify the key mechanisms of QE transmission. Along the way, we compute yields to maturity of different assets and bonds to observe the effects of QE policies on the term structure of interest rates. Our analysis of IRFs after a QE shock in an environment of financial frictions allows us to dissociate the standard credit channel from the rebalancing channel. This is done by reporting and comparing the IRFs of GKb to our dynamic. The work of GKb has only a credit channel, which means that any difference between our model and theirs will be related to the portfolio rebalancing channel. Our results show that the presence of securitization mechanisms coupled with a strong market segmentation significantly amplify the impacts of a QE shock to the economy via rebalancing effects. The latter also partially invert the yields curve.

The paper is organized as follows. Section 2 presents a literature review. Section 3 describes our empirical method and results. Section 4 describes the baseline DSGE model and discusses its calibration. Simulations are proposed in Section 5. Section 6 offers some concluding remarks.

\section{Literature review}

There are few papers using empirical models to quantify the portfolio rebalancing channel of QE transmission. A notable exception is Joyce et al. (2014), who examine portfolio reallocations induced by the Bank of England's QE policy. They provide evidence of portfolio rebalancing but limited to corporate bonds. D'Amico et al. (2012) estimate both duration and scarcity effects of QE programs in the US. Their results suggest sizable effects of QE1 and QE2 programs on long-term Treasury yields. Gagnon et al. (2011) estimate the overall size of the reduction in the 10-year term premium due to QE policies. They argue that their effects extend to the markets for treasuries, corporate bonds and swaps. Engen et al. (2015) use survey data to estimate changes in private expectations about the policy rule and the effects of QE programs on term premiums. They show that Large-Scale Asset Purchases (LSAPs) helped to stabilize the economy but failed to provide further monetary stimulation in the two years following the 2008 crisis in the US. They estimate that the full effects of QE occurred early 2015. They also argue that the Federal Open Market Committee is now more 
likely to tackle future crises using unconventional monetary policies. Peersman (2011) finds that an unconventional monetary policy in the Euro area has different transmission channels compared to conventional policies. He identifies a QE shock with the monetary base, then with an increase in the size of the central bank balance sheet, and finds that the effects of QE shocks on output and inflation are more persistent than in the US.

Most of the debate on the effects of QE policies is concentrated on theoretical papers. Cúrdia \& Woodford (2011) build a New Keynesian model with a role for the central bank in the determination of the equilibrium. In this specific framework, they show that QE policies have no role to play. However, they argue that a central bank intervention with QE produces benefits when a financial crisis hits the economy and the zero lower bound (ZLB) binds. In the same vein, Hilberg \& Hollmayr (2013) develop a DSGE model in which an interbank sector is central. They consider a "collateral" policy rule rather than a simple Taylor rule, and consider the potential benefits from including asset prices dynamics in the policy rule. They show that a central bank should provide liquidity when the economy experiences a bubble on asset prices. However, they claim that such a rule is inflationary, and therefore should not be implemented.

Different transmission channels are considered in the literature. Cúrdia et al. (2012) estimate a DSGE model in which the "preferred habitat" theory emerges. They find that LSAPs affect the economy due to limits to arbitrage and market segmentation between assets/bonds of different maturities. In addition, they argue that a commitment to a low nominal interest rate for a period of time leads QE programs to be at least twice as effective in affecting the economy. In his paper, Falagiarda (2013) builds a DSGE model that captures imperfect asset substitutability between government bonds of different maturities. His framework exhibits a portfolio rebalancing channel of QE policies. He also finds that the efficacy of QE policies crucially depends on the degree of substitutability among assets and exit delays. Harrison (2012) focuses on optimal policy in a New-Keynesian model that includes imperfect substitutability between short and long-term bonds. He finds that LSAPs paired with conventional monetary policy help mitigate outcomes arising from adverse shocks, especially when the ZLB is binding.

Few contributions explore the impact of a securitization mechanism on the transmission of crises and QE policies. Verona et al. (2013) propose a DSGE model in which bond financing depends on a shadow banking system. They calibrate two spreads on bonds for normal and optimistic times, and show that US boom-bust cycles are caused by (un)expected monetary policy shocks. They draw a lesson for monetary policy in which monetary authorities 
should imbed asset spreads in their policy rules to avoid over-confidence and risk underestimation. Meeks et al. (2014) develop a DSGE model with a stylized shadow banking sector. Brokers transform firm loans into Asset Backed Securities (ABS). They find that the pass-through effects depend on financial markets segmentation and are crucial for the dynamic of credit.

The role of the housing market is investigated by Iacoviello \& Neri (2008) among others, studying the sources and dynamics of fluctuations on this specific market. They estimate a DSGE model and show that, over the business cycle, half of the volatility in the housing market is explained by housing demand and technology shocks. In addition, they demonstrate that the contribution of monetary shocks to this volatility has been increasing over time and now represents around twenty per cent of the total volatility. Finally, they conclude that housing market spillovers have been growing over time and that they are rather concentrated on consumption. Dai et al. (2013) provide a DSGE model with a segmented financial intermediation and a housing market in the spirit of Iacoviello (2005). They consider an explicit mortgage market and a corporate loan market. They push their economy into financial disruption and simulate the effects of LSAPs of MBS and corporate bonds separately. They emphasize that the size of effects are crucially dependent on whether or not a portfolio rebalancing channel emerges. Moreover, when credit markets are fully segmented, they show that LSAPs have rather local effects and fail to support a global recovery.

Gertler \& Karadi (2011) (GKa) design a DSGE model with financial intermediaries that face endogenous constraints to their balance sheets. They simulate a typical financial crisis and evaluate the effects of a central bank credit intermediation. They also find that QE policies have larger effects when the ZLB is binding. In addition, GKb extend their baseline model to introduce limits to arbitrage between long-term government bonds and private securities, making LSAPs even more effective. They argue that LSAPs on bonds market are more qualitative than quantitative easing, and conclude that the main transmission channel of QE policies goes through reduced credit costs, i.e. the credit channel.

Despite the vast literature, none was found to clearly disentangle the credit and the portfolio rebalancing channels of QE transmission. The following sections address this issue and provide empirical and theoretical evidence of the rebalancing portfolio channel of QE. 


\section{A Bayesian VAR model}

\subsection{Specification of the model}

We run a BVAR analysis on US data with sign and zero restrictions for $m=1, \ldots, M$ variables. We allow for a restricted form of the VAR and stack all equations into matrices and vectors as:

$$
y_{t}=X_{t} \gamma+\epsilon_{t}
$$

where $\gamma$ is a $k \times 1$ vector of regression coefficients. $X_{t}$ is a $M \times k$ matrix with $k=\sum_{j=1}^{M} k_{j}$ that includes on its diagonal $x_{m t}$, the $k_{m}$-vector of the $t$ th observation of the vector of explanatory variables, $y_{t}$. We allow for flexible prior distributions of paramaters. Accordingly, we work with priors that ensure independance between the VAR coefficients and the variancecovariance matrix, i.e. the independent Normal-Wishart prior. We denote parameter priors with underbars. Our priors have the following form:

$$
\begin{gathered}
\gamma \sim \mathcal{N}\left(\underline{\gamma}, \underline{V}_{\gamma}\right) \\
\Sigma^{-1} \sim \mathcal{W}\left(\underline{S}^{-1}, \underline{\nu}\right)
\end{gathered}
$$

On the one hand, we apply the following prior hyperparameters $\underline{V}_{\gamma}=10 I_{K M}, \underline{\nu}=M+1$ and $\underline{S}^{-1}=I_{M}$. On the other hand, after detrending, our series show substantial persistence. Consequently, we set $\gamma$ for each variable with basic flavor of Minnesota priors (see Doan et al. (1983) and Litterman (1985)). The prior mean of the regression coefficient on its first own lag is set to be equal to its first value of its sample partial autocorrelation function, i.e. 0.89 for the real GDP per capita, 0.53 for the CPI growth rate, 0.80 and 0.78 respectively for each of the corporate spreads and 0.82 for the "government" spread.

\subsection{Data and Identification of a QE shock}

Our dataset is taken from the Federal Reserve Economic Data (FRED) website 1 . It features five US variables with quarterly observations starting from the first quarter of 1962 and ending the last quarter of 2007. Notice that post-crisis data is excluded from our analysis to be consistent with the mean calibration of our theoretical model presented in the next section. Our BVAR analysis includes data for real activity via the log of the real gross do-

\footnotetext{
${ }^{1}$ https://fred.stlouisfed.org/
} 
mestic product per capita (RGDP) and the log-difference of the consumer price index (CPI). We consider two corporate spreads: the spread between BAA and AAA Moody's seasoned corporate bond yields (BAA-AAA) and the spread between Moody's Seasoned BAA corporate bond yield and the 10-year Treasury constant maturity rate (BAA-10Y). We complete the dataset with a "government" spread between the 10-year Treasury constant maturity rate and the effective Federal Funds rate (10Y-FFR). All time series are detrended using a one-sided HP filter with a smoothing parameter $\lambda=1600^{2}$. Our choice of variables has been made to be consistent with our theoretical model, which will allow for a straightforward comparison of our empirical and theoretical IRFs. Details about the identification of the QE shock will be given in the next paragraph but we argue that a negative response of the BAA-AAA spread to such a shock would be considered a clear empirical evidence of the portfolio rebalancing channel of QE. Conversely, a muted or statistically non-significant response would indicate that this channel is absent.

Identification is achieved using an extension of the algorithm developed by Rubio-Ramírez et al. (2010) that solves for short and long-run restrictions. However, as mentioned in Canova (2007), DSGE models do not offer consistent short-run zero restrictions as in a Cholesky decomposition identification scheme in which strong assumptions on the location and the number of zero restrictions are imposed. To overcome these problems, we use a method suggested by Binning (2013), that allows for short and long-run restrictions along with sign-restrictions..$^{3}$ This tractable method allows to identify the single shock we are interested in, while preserving computational tractability. Table 1 summarizes the sign and zero restrictions imposed in the benchmark model. The sign restrictions are inspired by the theoretical model detailed in the next section.

A structural QE shock is assumed to produce a negative one standard deviation fall in the spread between the 10-year Treasury rate and the Federal Funds rate. In addition, the shock should raise real GDP for at least 4 quarters while its long-run effects must be null on this latter. Further, we wish for the shock to lower both corporate spreads for at least 4 quarters. The sign of the response of the inflation rate is left unrestricted. Our estimation uses a two-lags specification of the BVAR process, and includes a constant term. We compute 50 000 draws of the posterior distribution of the BVAR coefficients and IRFs and drop the first 10000 as burn-in. Our results are detailed in the next paragraph.

\footnotetext{
${ }^{2}$ The Matlab code was implemented by Meyer-Gohde (2010).

${ }^{3}$ Computer codes of the conditional posterior distribution of the coefficients and the Gibbs sampling algorithm are available upon request. See Binning (2013) for a complete and detailed description of the algorithm.
} 
Table 1: Identification scheme, Zero and Sign Restrictions

\begin{tabular}{cccc}
\hline \hline Variables & \multicolumn{3}{c}{ QE shock } \\
\hline Lero & Sign & Horizons \\
LR & & \\
\hline Real Gross Domestic Product per capita & 0 & $>0$ & 4 \\
Consumer Index Production & - & - & - \\
BAA - AAA & - & $<0$ & 4 \\
BAA - 10Y spread & - & $<0$ & 4 \\
10Y Treasury Constant Maturity Rate - Federal Funds rate & - & - & 4 \\
\hline \hline
\end{tabular}

\subsection{Results and comments}

Figure 1 presents the dynamics of the simulations. We report 16\%-84\% confidence intervals and median IRFs. On impact, the rise in real GDP is hump-shaped and slightly persistent following the imposed restrictions. Its magnitude reaches around two times the deviation in the "government" spread, showing the sizable effects of QE shocks on the real economy. The inflation rate co-moves with GDP for some periods. Hence, an accommodating QE shock generates little inflation. Our key variables of interest, i.e. corporate spreads, show statistically significant responses that are consistent with our set of restrictions. The BAA$10 \mathrm{Y}$ index of performance of corporate bonds in market can be viewed as a proxy of credit costs to firms or the external finance premium. Given this assumption, its drop confirms that the economy is impacted via the credit channel of QE transmission. Moreover, the fall in the BAA-AAA spread suggests that another transmission mechanism is at work. Intuitively, if we consider only the credit channel of QE policies, all else being equal, a QE shock would ultimately put a similar pressure on yields, shifting the yield curve but preserving its shape. In this scenario, the BAA-AAA spread would show a non-significant or zero response to the shock which is actually not the case. We then claim that the decrease in BAA-AAA spread provides empirical evidence of the portfolio rebalancing channel of QE transmission. Thus, a purchase of long-term government bonds not only affects its yields but also those of assets that are close substitutes with different intensities. In other words, this suggests that investors lower the share of government bonds in their portfolios and raise the share of high-quality and relatively safe corporate bonds. 
Figure 1: BVAR impulse response functions

(a) Output

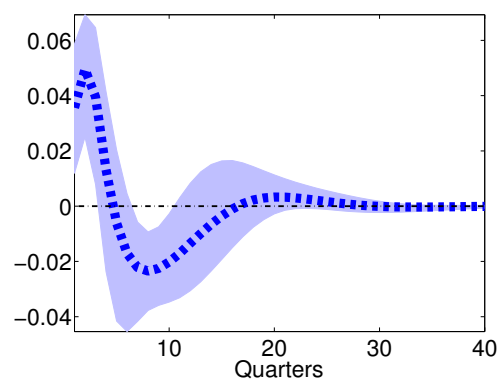

(b) Inflation Rate

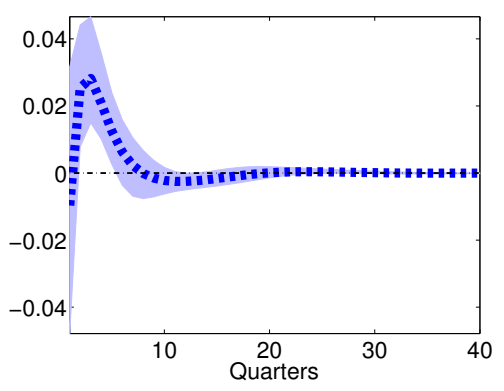

(c) BAA-AAA

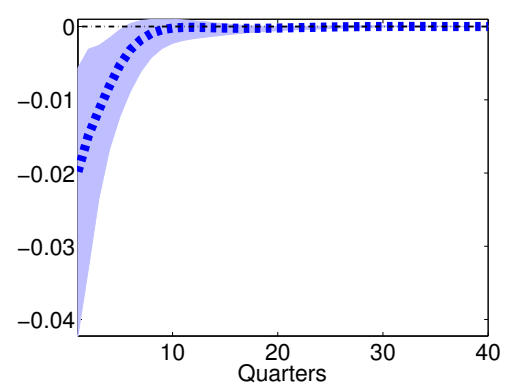

(d) BAA-10Y

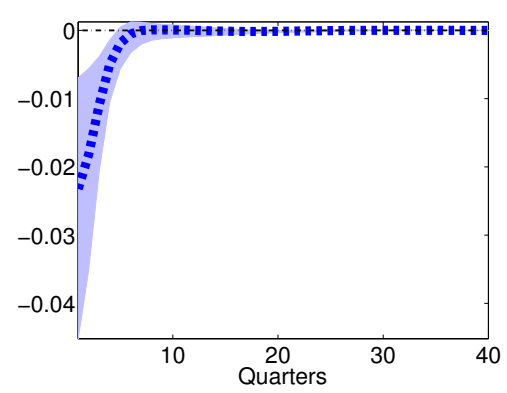

(e) 10Y-FFR

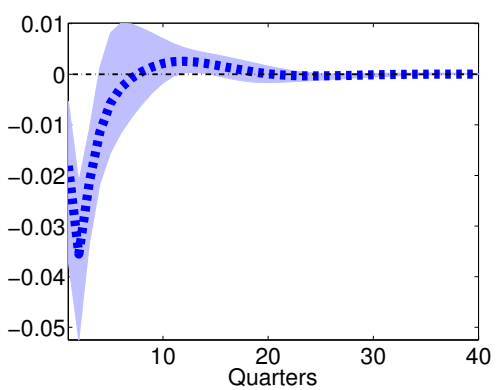

Blue dotted line: median of the impulse response functions.

\section{Model}

We now want to confront the empirical IRFs uncovered in the previous section to the predictions of a calibrated DSGE model with financial fricitions. The model is based on GKb, who propose a clear, simple, yet relatively general macroeconomic model that captures multiple features of the recent financial crisis and show how LSAPs channel to the real economy. Our main objective is to dissociate the credit channel and the portfolio rebalancing channel of QE transmission. To do so, we introduce securitization mechanisms. First, we model Special Purpose Entities (SPE), that transform a pool of loans into ABS along the lines of Meeks et al. (2014). In addition, we introduce Government-Sponsored Enterprises (GSE) that transform housing mortgages into MBS. The housing sector is modelled after Iacoviello $\&$ Neri (2008). These different assets and frictions will allow us to differentiate the effects of QE policies on different spreads, and help distinguish the portfolio rebalancing channel from the standard credit channel. 


\subsection{Commercial banks}

Commercial banks (c) collect households deposits and grant loans to firms and mortgages to households. In addition to these lending activities, commercial banks hold a stock of long-term government bonds. We consider a continuum of identical commercial banks and define the typical balance sheet of a commercial bank as:

$$
Q_{t} s_{t}^{c}+q_{t}^{h} h_{t}^{c}+q_{t}^{m b s} m_{t}^{m b s, c}+q_{t}^{a b s} a_{t}^{a b s, c}+q_{t}^{b} b_{t}^{c}=d_{t}+n_{t}^{c}
$$

The asset side features corporate securities $s_{t}^{c}$, housing mortgages $h_{t}^{c}$, quantities of MBS $m_{t}^{m b s, c}$ and ABS $a_{t}^{a b s, c}$ and long-term government bonds $b_{t}^{c}$. The market prices of these assets are $Q_{t}, q_{t}^{h}, q_{t}^{m b s}, q_{t}^{a b s}$ and $q_{t}^{b}$ respectively . The liability side is made of households' short-term deposits $d_{t}$ and of commercial banks net worth $n_{t}^{c}$. Its evolution is given by:

$$
\begin{aligned}
n_{t}^{c} & =R_{s t} Q_{t-1} s_{t-1}^{c}+R_{h t} q_{t-1}^{h} h_{t-1}^{c}+R_{m t} q_{t-1}^{m b s} m_{t-1}^{m b s, c}+R_{a t} q_{t-1}^{a b s} a_{t-1}^{a b s, c}+R_{b t} q_{t-1}^{b} b_{t-1}^{c}-R_{t} d_{t-1} \\
& =\left(R_{s t}-R_{t}\right) Q_{t-1} s_{t-1}^{c}+\left(R_{h t}-R_{t}\right) q_{t-1}^{h} h_{t-1}^{c}+\left(R_{m t}-R_{t}\right) q_{t-1}^{m b s} m_{t-1}^{m b s, c}+\left(R_{a t}-R_{t}\right) q_{t-1}^{a b s} a_{t-1}^{a b s, c} \\
& +\left(R_{b t}-R_{t}\right) q_{t-1}^{b} b_{t-1}^{c}+R_{t} n_{t-1}^{c}
\end{aligned}
$$

where $R_{s t}$ is the stochastic return on corporate securities, $R_{h t}$ on housing mortgages, $R_{m t}$ on MBS, $R_{a t}$ on ABS and $R_{b t}$ on long-term bonds. Long-term bonds are perpetuities that yield a one-dollar coupon payment per period, such that:

$$
R_{b t+1}=\frac{\frac{1}{P_{t}}+q_{t+1}^{b}}{q_{t}^{b}}
$$

Bankers maximize the discounted stream of dividends paid to households at the stochastic discount factor $\Lambda_{t, t+i}$ subject to a survival probability $\sigma$. The problem is denoted as:

$$
V_{t}^{c}=\max \mathbb{E}_{t} \sum_{i=1}^{\infty}(1-\sigma) \sigma^{i-1} \Lambda_{t, t+i}\left(n_{t+i}^{c}\right)
$$

Equation (5) shows that bankers can make infinite profits due to arbitrage opportunities. As in GKb, we limit this possibility by introducing a moral hazard problem by which a banker can divert a fraction $\theta_{c}$ of its total assets. As in Meeks et al. (2014), we introduce a weight $\Theta<1$ according to which a commercial banker is more likely to divert corporate securities than ABS. Parameter $\Delta<1$ is also introduced so that a commercial banker can divert a lower fraction of government bonds. On the contrary, we assume that a commercial banker has the opportunity to divert a greater portion of MBS and housing mortgages through the 
introduction of the weights $\Xi>1$ and $\Phi>1$. Following GKb, we claim and verify that $V_{t}^{c}$ is linear in the marginal values of assets $\left(\mu_{s t}^{c}, \mu_{h t}^{c}, \mu_{m t}^{c}, \mu_{a t}^{c}, \mu_{b t}^{c}\right)$ and in equity capital, $\eta_{t}^{c}$. Overall, households are willing to deposit if the following constraint holds:

$$
\begin{aligned}
V_{t}^{c} & =\mu_{s t}^{c} Q_{t} s_{t}^{c}+\mu_{h t}^{c} q_{t}^{h} h_{t}^{c}+\mu_{m t}^{c} q_{t}^{m b s} m_{t}^{m b s, c}+\mu_{a t}^{c} q_{t}^{a b s} a_{t}^{a b s, c}+\mu_{b t}^{c} q_{t}^{b} b_{t}^{c}+\eta_{t}^{c} n_{t}^{c} \\
& \geq \theta_{c}\left(Q_{t} s_{t}^{c}+\Phi q_{t}^{h} h_{t}^{c}+\Xi q_{t}^{m b s} m_{t}^{m b s, c}+\Theta q_{t}^{a b s} a_{t}^{a b s, c}+\Delta q_{t} b_{t}^{c}\right)
\end{aligned}
$$

The incentive constraint always binds in equilibrium. Accordingly, the optimization problem yields the following first order conditions respectively for $s_{t}^{c}, h_{t}^{c}, m_{t}^{c}, a_{t}^{c}, b_{t}^{c}, \lambda_{t}^{c}$ :

$$
\begin{aligned}
\mu_{s t}^{c} & =\frac{\lambda_{t}^{c}}{1+\lambda_{t}^{c}} \theta_{c} \\
\mu_{h t}^{c} & =\frac{\lambda_{t}^{c}}{1+\lambda_{t}^{c}} \theta_{c} \Phi \\
\mu_{m t}^{c} & =\frac{\lambda_{t}^{c}}{1+\lambda_{t}^{c}} \theta_{c} \Xi \\
\mu_{a t}^{c} & =\frac{\lambda_{t}^{c}}{1+\lambda_{t}^{c}} \theta_{c} \Theta \\
\mu_{b t}^{c} & =\frac{\lambda_{t}^{c}}{1+\lambda_{t}^{c}} \theta_{c} \Delta \\
\left(\mu_{s t}^{c}-\theta_{c}\right) Q_{t} s_{t}^{c}+\left(\mu_{h t}^{c}-\theta_{c} \Phi\right) q_{t}^{h} h_{t}^{c}+\left(\mu_{m t}^{c}\right. & \left.-\theta_{c} \Xi\right) q_{t}^{m b s} m_{t}^{m b s, c}+\left(\mu_{a t}^{c}-\theta_{c} \Theta\right) q_{t}^{a b s} a_{t}^{a b s, c} \\
&
\end{aligned}
$$

Rearranging Equation (14) gives:

$$
Q_{t} s_{t}^{c}+\Phi q_{t}^{h} h_{t}^{c}+\Xi q_{t}^{m b s} m_{t}^{m b s, c}+\Theta q_{t}^{a b s} a_{t}^{a b s, c}+\Delta q_{t}^{b} b_{t}^{c}=\phi_{t}^{c} n_{t}^{c}
$$

where,

$$
\phi_{t}^{c}=\frac{\eta_{t}^{c}}{\theta_{c}-\mu_{s t}^{c}}
$$

as well as,

$$
\phi_{t}^{c}=\frac{\mathbb{E}_{t} \Lambda_{t, t+1} \Omega_{t+1}^{c} R_{t+1}}{\theta_{c}-\mathbb{E}_{t} \Lambda_{t, t+1} \Omega_{t+1}^{c}\left(R_{s t+1}-R_{t+1}\right)}
$$


in which $\phi_{t}^{c}$ is the leverage ratio of corporate securities over net worth. After few rearrangements, the Bellman Equation (7) gives the optimal conditions for each marginal value:

$$
\begin{aligned}
\mu_{s t}^{c} & =\mathbb{E}_{t} \Lambda_{t, t+1} \Omega_{t+1}^{c}\left(R_{s t+1}-R_{t+1}\right) \\
\mu_{h t}^{c} & =\mathbb{E}_{t} \Lambda_{t, t+1} \Omega_{t+1}^{c}\left(R_{h t+1}-R_{t+1}\right) \\
\mu_{m t}^{c} & =\mathbb{E}_{t} \Lambda_{t, t+1} \Omega_{t+1}^{c}\left(R_{m t+1}-R_{t+1}\right) \\
\mu_{a t}^{c} & =\mathbb{E}_{t} \Lambda_{t, t+1} \Omega_{t+1}^{c}\left(R_{a t+1}-R_{t+1}\right) \\
\mu_{b t}^{c} & =\mathbb{E}_{t} \Lambda_{t, t+1} \Omega_{t+1}^{c}\left(R_{b t+1}-R_{t+1}\right) \\
\eta_{t}^{c} & =\mathbb{E}_{t} \Lambda_{t, t+1} \Omega_{t+1}^{c} R_{t+1}
\end{aligned}
$$

where,

$$
\Omega_{t}^{c}=(1-\sigma)+\sigma \frac{\partial V_{t}^{c}}{\partial n_{t}^{c}}
$$

and,

$$
\frac{\partial V_{t}^{c}}{\partial n_{t}^{c}}=\mu_{s t}^{c} \phi_{t}^{c}+\eta_{t}^{c}
$$

The problem is isomorphic to all commercial banks. Hence, summing across portfolio restrictions and individual demands on each commercial bank, we obtain:

$$
Q_{t} S_{t}^{c}+\Phi q_{t}^{h} H_{t}^{c}+\Xi q_{t}^{m b s} M_{t}^{m b s, c}+\Theta q_{t}^{a b s} A_{t}^{a b s, c}+\Delta q_{t}^{b} B_{t}^{c}=\phi_{t}^{c} N_{t}^{c}
$$

After few rearrangements, we find the demand for MBS:

$$
q_{t}^{m b s} M_{t}^{m b s, c}=\frac{(1-\Phi) q_{t}^{h} H_{t}^{c}+(1-\Theta) q_{t}^{a b s} A_{t}^{a b s, c}+(1-\Delta) q_{t}^{b} B_{t}^{c}+\left(\phi_{t}^{c}-1\right) N_{t}^{c}-D_{t}}{\Xi-1}
$$

Similarly, the demand for ABS writes:

$$
q_{t}^{a b s} A_{t}^{a b s, c}=\frac{(1-\Phi) q_{t}^{h} H_{t}^{c}+(1-\Xi) q_{t}^{m b s} M_{t}^{m b s, c}+(1-\Delta) q_{t}^{b} B_{t}^{c}+\left(\phi_{t}^{c}-1\right) N_{t}^{c}-D_{t}}{\Theta-1}
$$

In this framework, when the constraint is binding, a central bank asset purchase is efficient by reducing excessive financial spreads. Given the constrained amount of banks equity capital, QE shocks directly distort the relative prices of assets. It is then intuitive that the efficacy of QE policies emerges from the presence of frictions to arbitrage among assets. On the contrary, in a frictionless environment, demands for assets would increase one by one with the assets holdings of the central bank. In addition, we obtain the following arbitrage identities with equations from $(18)$ to $(23)$ which underlines the role of frictions in the overall 
dynamic of financial markets:

$$
\begin{aligned}
\mathbb{E}_{t} \Lambda_{t, t+1} \Omega_{t+1}^{c}\left(R_{h t+1}-R_{t+1}\right) & =\Phi \mathbb{E}_{t} \Lambda_{t, t+1} \Omega_{t+1}^{c}\left(R_{s t+1}-R_{t+1}\right) \\
\mathbb{E}_{t} \Lambda_{t, t+1} \Omega_{t+1}^{c}\left(R_{m t+1}-R_{t+1}\right) & =\Xi \mathbb{E}_{t} \Lambda_{t, t+1} \Omega_{t+1}^{c}\left(R_{s t+1}-R_{t+1}\right) \\
\mathbb{E}_{t} \Lambda_{t, t+1} \Omega_{t+1}^{c}\left(R_{a t+1}-R_{t+1}\right) & =\Theta \mathbb{E}_{t} \Lambda_{t, t+1} \Omega_{t+1}^{c}\left(R_{s t+1}-R_{t+1}\right) \\
\mathbb{E}_{t} \Lambda_{t, t+1} \Omega_{t+1}^{c}\left(R_{b t+1}-R_{t+1}\right) & =\Delta \mathbb{E}_{t} \Lambda_{t, t+1} \Omega_{t+1}^{c}\left(R_{s t+1}-R_{t+1}\right)
\end{aligned}
$$

Given that, the extent of financial frictions matters for the efficacy of the central bank unconventional programs. Assuming this framework, the financial spreads on government bonds and $\mathrm{ABS}$ are fractions $\Delta, \Theta<1$ of the spread on corporate securities. Moreover, the financial spreads on mortgage loans and MBS are weighted by $\Phi, \Xi>1$. Accordingly, everything else being equal, government bonds and ABS yields will decrease less than the yield on coporate securities following a QE targeted on this latter. On the contrary, the yields on mortgage loans and MBS will be highly impaired on impact. Overall, the emergence of differences among relative prices of assets is the linchpin of the portfolio rebalancing channel of QE policies.

\subsection{Special Purpose Entities}

A Special Purpose Entity (SPE) is in charge of the securitization of ABS. Identical loan brokers populate the SPE. We define a single balance sheet as:

$$
Q_{t} s_{t}^{a}=n_{t}^{a}+q_{t}^{a b s} a_{t}^{a b s, a}
$$

The asset side features a pool of loans $s_{t}^{a}$. The liability side is composed of ABS $a_{t}^{a b s, a}$ and net worth $n_{t}^{a}$, evolving according to:

$$
\begin{aligned}
n_{t}^{a} & =R_{s t} Q_{t-1} s_{t-1}^{a}-R_{a t} q_{t-1}^{a b s} a_{t-1}^{a b s, a} \\
& =\left(R_{s t}-R_{a t}\right) Q_{t-1} s_{t-1}^{a}+R_{a t} n_{t-1}^{a}
\end{aligned}
$$

As in the case of commercial bankers, loan brokers face the same survival probability $\sigma$, and maximize the discounted stream of dividends they pay to households at the stochastic discount factor $\Lambda_{t, t+i}$. The problem is written as:

$$
V_{t}^{a}=\max \mathbb{E}_{t} \sum_{i=1}^{\infty}(1-\sigma) \sigma^{i-1} \Lambda_{t, t+i}\left(n_{t+i}^{a}\right)
$$


Again, Equation (34) shows that mortgage brokers can make infinite profits from the securitization of corporate securities. We limit this opportunity by allowing loan brokers to divert a fraction $\theta_{a}$ of their assets. We claim and verify that the value function is linear in the marginal values of its arguments $\left(\mu_{s t}^{a}, \nu_{a t}^{a}\right)$ in which $\mu_{s t}^{a}=\nu_{s t}^{a} / Q_{t}-\nu_{a t}^{a} / q_{t}^{a b s}$ is the excess value of pool of loans over ABS. Overall, the securitization mechanism is effective if the following constraint holds:

$$
V_{t}^{a}=\mu_{s t}^{a} Q_{t} s_{t}^{a}+\frac{\nu_{a t}^{a}}{q_{t}^{a b s}} n_{t}^{a} \geq \theta_{a} Q_{t} s_{t}^{a}
$$

The incentive constraint always binds in equilibrium. The optimization problem produces the following first order conditions for $s_{t}^{a}$ and $\lambda_{t}^{a}$ :

$$
\begin{array}{r}
\mu_{s t}^{a}=\frac{\lambda_{t}^{a}}{1+\lambda_{t}^{a}} \theta_{a} \\
\left(\mu_{s t}^{a}-\theta_{a}\right) Q_{t} s_{t}^{a}+\frac{\nu_{a t}^{a}}{q_{t}^{a b s}} n_{t}^{a}=0
\end{array}
$$

We rearrange Equation 38 to find the demand for pool of loans:

$$
Q_{t} s_{t}^{a}=\phi_{t}^{a} n_{t}^{a}
$$

where,

$$
\phi_{t}^{a}=\frac{\nu_{a t}^{a} / q_{t}^{a b s}}{\theta_{a}-\mu_{s t}^{a}}
$$

as well as,

$$
\phi_{t}^{a}=\frac{\mathbb{E}_{t} \Lambda_{t, t+1} \Omega_{t+1}^{a} R_{a t+1}}{\theta_{a}-\mathbb{E}_{t} \Lambda_{t, t+1} \Omega_{t+1}^{a}\left(R_{s t+1}-R_{a t+1}\right)}
$$

in which $\phi_{t}^{a}$ is the endogenous leverage ratio of pool of loans over net worth. After rearrangements, the Bellman Equation (35) yields the following optimal conditions for each marginal value:

$$
\begin{aligned}
\mu_{s t}^{a} & =\mathbb{E}_{t} \Lambda_{t, t+1} \Omega_{t+1}^{a}\left(R_{s t+1}-R_{a t+1}\right) \\
\frac{\nu_{a t}^{a}}{q_{t}^{a b s}} & =\mathbb{E}_{t} \Lambda_{t, t+1} \Omega_{t+1}^{a} R_{a t+1}
\end{aligned}
$$

where,

$$
\Omega_{t}^{a}=(1-\sigma)+\sigma \frac{\partial V_{t}^{a}}{\partial n_{t}^{a}}
$$

and,

$$
\frac{\partial V_{t}^{a}}{\partial n_{t}^{a}}=\mu_{s t}^{a} \phi_{t}^{a}+\frac{\nu_{a t}^{a}}{q_{t}^{a b s}}
$$


The problem is isomorphic to all SPEs. Hence, summing across portfolio restrictions and individual demands on each SPE to obtain:

$$
Q_{t} S_{t}^{a}=\phi_{t}^{a} N_{t}^{a}
$$

After few rearrangements we find the issuance identity of ABS:

$$
q_{t}^{a b s} A_{t}^{a b s, a}=\left(\frac{\phi_{t}^{a}-1}{\phi_{t}^{a}}\right) Q_{t} S_{t}^{a}
$$

\subsection{Government-Sponsored Enterprises}

A Government-Sponsored Enterprise (GSE) is in charge of the securitization of MBS. There is a continuum of identical GSE and mortgage brokers populate GSEs. We define a single balance sheet as:

$$
q_{t}^{h} h_{t}^{h}=n_{t}^{h}+q_{t}^{m b s} m_{t}^{m b s, h}
$$

The asset side features a pool of mortgage loans $h_{t}^{h}$. The liability side is composed of MBS $m_{t}^{m b s, h}$ and net worth $n_{t}^{h}$, that evolves according to:

$$
\begin{aligned}
n_{t}^{h} & =R_{h t} q_{t-1}^{h} h_{t-1}^{h}-R_{m t} q_{t-1}^{m b s} m_{t-1}^{m b s, h} \\
& =\left(R_{h t}-R_{m t}\right) q_{t-1}^{h} h_{t-1}^{h}+R_{m t} n_{t-1}^{h}
\end{aligned}
$$

where the stochastic return on MBS is $R_{m t}$. MBS are perpetuities that yields a $\Xi_{m}$ coupon payment per period, such as:

$$
R_{m t+1}=\frac{\Xi_{m}+q_{t+1}^{m b s}}{q_{t}^{m b s}}
$$

Again, mortgage brokers face the same survival probability $\sigma$ and maximize the discounted stream of dividends paid to households at the stochastic discount factor $\Lambda_{t, t+i}$. The problem writes:

$$
V_{t}^{h}=\max \mathbb{E}_{t} \sum_{i=1}^{\infty}(1-\sigma) \sigma^{i-1} \Lambda_{t, t+i}\left(n_{t+i}^{h}\right)
$$

Equation (49), shows that brokers can make infinite profits from the securitization of mortgages. We limit this opportunity by allowing mortgage brokers to divert a fraction $\theta_{h}$ of their assets. We claim and verify that the value function is linear in the marginal values of its arguments $\left(\mu_{h t}^{h}, \nu_{m t}^{h}\right)$ in which $\mu_{h t}^{h}=\nu_{h t}^{h} / Q_{t}-\nu_{m t}^{h} / q_{t}^{m b s}$ is the excess value of pool of mortgages over MBS. Overall, the securitization of mortgages is effective if the following 
constraint holds:

$$
V_{t}^{h}=\mu_{h t}^{h} q_{t}^{h} h_{t}^{h}+\frac{\nu_{m t}^{h}}{q_{t}^{m b s}} n_{t}^{h} \geq \theta_{h} q_{t}^{h} h_{t}^{h}
$$

The incentive constraint always binds in equilibrium. The optimization problem produces the following first order conditions for $h_{t}^{h}$ and $\lambda_{t}^{h}$ :

$$
\begin{array}{r}
\mu_{h t}^{h}=\frac{\lambda_{t}^{h}}{1+\lambda_{t}^{h}} \theta_{h} \\
\left(\mu_{h t}^{h}-\theta_{h}\right) q_{t}^{h} h_{t}^{h}+\frac{\nu_{m t}^{h}}{q_{t}^{m b s}} n_{t}^{h}=0
\end{array}
$$

We rearrange Equation (54) and find the demand for the pool of mortgages:

$$
q_{t}^{h} h_{t}^{h}=\phi_{t}^{h} n_{t}^{h}
$$

where,

$$
\phi_{t}^{h}=\frac{\nu_{m t}^{h} / q_{t}^{m b s}}{\theta_{h}-\mu_{h t}^{h}}
$$

as well as,

$$
\phi_{t}^{h}=\frac{\mathbb{E}_{t} \Lambda_{t, t+1} \Omega_{t+1}^{h} R_{m t+1}}{\theta_{h}-\mathbb{E}_{t} \Lambda_{t, t+1} \Omega_{t+1}^{h}\left(R_{s t+1}-R_{m t+1}\right)}
$$

in which $\phi_{t}^{h}$ is the endogenous leverage ratio of pool of mortgages over net worth. After rearrangements, the Bellman Equation (51) yields to the following optimal conditions for each marginal value:

$$
\begin{aligned}
\mu_{h t}^{h} & =\mathbb{E}_{t} \Lambda_{t, t+1} \Omega_{t+1}^{h}\left(R_{s t+1}-R_{m t+1}\right) \\
\frac{\nu_{m t}^{h}}{q_{t}^{m b s}} & =\mathbb{E}_{t} \Lambda_{t, t+1} \Omega_{t+1}^{h} R_{m t+1}
\end{aligned}
$$

where,

$$
\Omega_{t}^{h}=(1-\sigma)+\sigma \frac{\partial V_{t}^{h}}{\partial n_{t}^{h}}
$$

and,

$$
\frac{\partial V_{t}^{h}}{\partial n_{t}^{h}}=\mu_{h t}^{h} \phi_{t}^{h}+\frac{\nu_{m t}^{h}}{q_{t}^{m b s}}
$$

The problem is isomorphic to all GSEs. Hence, summing across portfolio restrictions and individual demands on each GSE gives:

$$
q_{t}^{h} H_{t}^{h}=\phi_{t}^{h} N_{t}^{h}
$$


After rearrangements we find the issuance identity of MBS:

$$
q_{t}^{m b s} M_{t}^{m b s, h}=\left(\frac{\phi_{t}^{h}-1}{\phi_{t}^{h}}\right) q_{t}^{h} H_{t}^{h}
$$

\subsection{Households}

There is a unit mass of identical households that switch occupations. They are either workers, bankers, loan brokers or mortgage brokers, and the switching probability is $\sigma$. A representative worker buys consumption goods, chooses a housing stock and adjusts its supply of hours worked to maximize lifetime welfare:

$$
\mathcal{U}_{t}=\max \mathbb{E}_{t} \sum_{i=0}^{\infty} \beta^{i}\left[\ln \left(C_{t+i}-h C_{t+i-1}\right)-\frac{\chi}{1+\varphi} L_{t+i}^{1+\varphi}+j^{h} \frac{h_{t+i}^{1-\zeta}}{1-\zeta}\right]
$$

where $C_{t}$ is the consumption of goods, subject to habit formation of intensity $h, L_{t}$ is the number of hours worked and $h_{t}$ is the housing stock. Let $\beta \in[0,1]$ be households discount factor, and $\chi, \varphi, \zeta>0$ be preference parameters. Welfare maximization is achieved subject to the following intertemporal budget constraint:

$$
\begin{aligned}
C_{t}+D_{t}+q_{t}^{h}\left(h_{t}-h_{t-1}\right) & +R_{t}^{h} H_{t-1}+Q_{t}\left(S_{t}^{h}+\frac{1}{2} \kappa\left(S_{t}^{h}-\bar{S}^{h}\right)^{2}\right)+q_{t}^{b}\left(B_{t}^{h}+\frac{1}{2} \kappa\left(B_{t}^{h}-\bar{B}^{h}\right)^{2}\right) \\
& =W_{t} L_{t}+\Pi_{t}^{h}+T_{t}+R_{t} D_{t-1}+R_{s t} S_{t-1}^{h}+R_{b t} B_{t-1}^{h}+H_{t}
\end{aligned}
$$

where $W_{t}$ stands for the real wage, $T_{t}$ denotes lump-sum taxes and $\Pi_{t}^{h}$ defines the payouts from final goods producers and the financial sector. Let $D_{t}$ be the amount of deposits to commercial banks that pay a riskless real interest rate $R_{t}$. We allow households to hold primary securities and long-term government bonds subject to quadratic adjustment costs $\frac{1}{2} \kappa\left(S_{t}^{h}-\bar{S}^{h}\right)^{2} / S_{t}^{h}$ and $\frac{1}{2} \kappa\left(B_{t}^{h}-\bar{B}^{h}\right)^{2} / B_{t}^{h}$. Holding these assets respectively pays $R_{s t}$ and $R_{b t}$. In addition, workers accumulate housing with mortgage loans $H_{t}$ granted by commercial banks. Their borrowing capacity is constrained by the expected value of their housing stock adjusted by the loan-to-value ratio $\mu$. The borrowing constraint is given by:

$$
R_{t+1}^{h} H_{t} \leq \mu \mathbb{E}_{t} q_{t+1}^{h} h_{t}
$$

and states that the total value of mortgage payments must not exceed a fraction $\mu$ of the total value of the housing stock. Let $\varrho_{t}$ be the marginal utility of consumption and $\Lambda_{t}$ the stochastic (utility-adjusted) discount factor. Overall, household's first order conditions for 
$L_{t}, C_{t}, h_{t}$ and $D_{t}$ are:

$$
\begin{aligned}
\chi L_{t}^{\varphi} & =W_{t} \varrho_{t} \\
\varrho_{t}= & \left(C_{t}-h C_{t-1}\right)^{-1}-\beta h \mathbb{E}_{t}\left(C_{t+1}-h C_{t}\right)^{-1} \\
q_{t}^{h}= & \frac{j^{h} h_{t}^{-\zeta}}{\varrho_{t}}+\mathbb{E}_{t} \Lambda_{t, t+1} q_{t+1}^{h}+\left(1-\mathbb{E}_{t} \Lambda_{t, t+1} R_{h t+1}\right) \frac{H_{t}}{h_{t}} \\
& \quad \mathbb{E}_{t} \Lambda_{t, t+1} R_{t+1}=1
\end{aligned}
$$

where,

$$
\mathbb{E}_{t} \Lambda_{t, t+1}=\beta \frac{\varrho_{t+1}}{\varrho_{t}}
$$

Finally, the choices for financial securities and long-term government bonds $S_{t}^{h}$ and $B_{t}^{h}$ are:

$$
\begin{aligned}
S_{t}^{h} & =\bar{S}^{h}+\frac{\mathbb{E}_{t} \Lambda_{t, t+1}\left(R_{s t+1}-R_{t+1}\right)}{\kappa} \\
B_{t}^{h} & =\bar{B}^{h}+\frac{\mathbb{E}_{t} \Lambda_{t, t+1}\left(R_{b t+1}-R_{t+1}\right)}{\kappa}
\end{aligned}
$$

\subsection{Intermediate goods producers}

Intermediate goods producers use labor $L_{t}$ and effective capital $K_{t}$ to produce the intermediate good $Y_{t}$. The output is sold to monopolistically competitive retailers at the relative price $P_{m t}$. The production function is:

$$
Y_{t}=A_{t} K_{t}^{\alpha} L_{t}^{1-\alpha}
$$

where $A_{t}$ is the total factor productivity. The first-order conditions with respect to labor and capital write:

$$
\begin{aligned}
W_{t} & =(1-\alpha) P_{m t} \frac{Y_{t}}{L_{t}} \\
Z_{t} & =\alpha P_{m t} \frac{Y_{t}}{K_{t}}
\end{aligned}
$$

At the end of the period, intermediate goods producers carry a capital stock $(1-\delta) K_{t}$. They must buy $I_{t}$ new units of capital from capital producers. Accordingly, the law motion of capital is:

$$
K_{t+1}=(1-\delta) K_{t}+I_{t}
$$


For each new unit of capital, goods producers issue a state-contingent security. The value of a securitiy is the market price $Q_{t}$. Because of competition, intermediate goods producers earn zero profits. The terminal payoff is equal to the sum of gross profits and the market value of the ex-ante capital stock $\left(Z_{t+1}+(1-\delta) Q_{t+1}\right)$. Thus, the real rate of return to the commercial bank security is:

$$
R_{s t+1}=\frac{Z_{t+1}+(1-\delta) Q_{t+1}}{Q_{t}}
$$

Accordingly, the real return on ABS is:

$$
R_{a t+1}=\frac{Z_{t+1}+(1-\delta) q_{t+1}^{a b s}}{q_{t}^{a b s}}
$$

\subsection{Capital goods producers}

Capital goods producers build new capital and sell it to intermediate goods producers at the market price $Q_{t}$, as stated previously. They acquire the depreciated capital and final output from retailers as inputs. Moreover, they are subject to increasing convex adjustment costs. Capital goods producers choose $I_{t}$ and maximize:

$$
\max \mathbb{E}_{t} \sum_{\tau=t}^{\infty} \Lambda_{t, \tau}\left\{Q_{\tau}^{i} I_{\tau}-\left[1+f\left(\frac{I_{\tau}}{I_{\tau-1}}\right)\right] I_{\tau}\right\}
$$

Optimization yields to the price of capital goods:

$$
Q_{t}=1+f\left(\frac{I_{t}}{I_{t-1}}\right)+\left(\frac{I_{t}}{I_{t-1}}\right) f^{\prime}\left(\frac{I_{t}}{I_{t-1}}\right)-\mathbb{E}_{t} \Lambda_{t, t+1}\left(\frac{I_{t+1}}{I_{t}}\right)^{2} f^{\prime}\left(\frac{I_{t+1}}{I_{t}}\right)
$$

\subsection{Retail firms}

Retailers provide a final output to the economy. The latter is given from a repackaging of intermediate goods. The process evolves with:

$$
Y_{t}=\left[\int_{0}^{1} Y_{f t}^{\frac{\varepsilon-1}{\varepsilon}} d f\right]^{\frac{\varepsilon}{\varepsilon-1}}
$$

where $Y_{f t}$ is the final output for each retailer $f$, and where $\varepsilon$ is the elasticity of substitution between retail goods. We introduce nominal rigidities with price contracts à la Calvo (1983). 
Accordingly, a firm can adjust its price with probability $1-\gamma^{p}$. Thus, each firm chooses an optimal reset price $P_{t}^{*}$ subject to the above-mentioned restrictions. The optimal pricing contract maximizes:

$$
\sum_{i=0}^{\infty} \gamma^{p, i} \Lambda_{t, t+i}\left[\frac{P_{t}^{*}}{P_{t+i}}-\mu^{p} P_{m t+i}\right] Y_{f t+1}=0
$$

The law of large numbers gives the standard relation of price level dynamic:

$$
P_{t}=\left[\left(1-\gamma^{p}\right)\left(P_{t}^{*}\right)^{1-\varepsilon}+\gamma^{p}\left(P_{t-1}\right)^{1-\varepsilon}\right]^{\frac{1}{1-\varepsilon}}
$$

\subsection{Government policy}

We assume standard monetary policy by a central bank that follows a Taylor Rule with a smoothing parameter $\rho$ :

$$
i_{t}=(1-\rho)\left(\bar{i}+\kappa_{\pi} \pi_{t}+\kappa_{y}\left(\log Y_{t}-\log Y_{t}^{*}\right)\right)+\rho i_{t-1}
$$

where $Y_{t}^{*}$ is the flexible price level of output. In addition, the central bank is able to purchase a given amount of corporate securities, $S_{t}^{g}$, mortgage loans $H_{t}^{g}$, ABS, $A_{t}^{a b s, g}$, MBS, $M_{t}^{m b s, g}$ and long-term government bonds, $B_{t}^{g}$. The government finances the purchases via a riskless short-term obligation held by households $D_{t}^{g}$. The central bank's balance sheet is therefore given by:

$$
D_{t}^{g}=Q_{t} S_{t}^{g}+q_{t}^{h} H_{t}^{g}+q_{t}^{a b s} A_{t}^{a b s, g}+q_{t}^{m b s} M_{t}^{m b s, g}+q_{t}^{b} B_{t}^{g}
$$

The central bank is not balance sheet constrained and transfers back earnings to the government. In other words, the central bank can elastically obtain funds from households through short-term bond issuance. Let $\psi_{i t}$ be the exogenous fractions of the respective assets the central bank can purchase. The amounts of purchases are:

$$
\begin{aligned}
S_{t}^{g} & =\psi_{s t}\left(S_{t}^{c}+S_{t}^{h}+S_{t}^{a}\right) \\
H_{t}^{g} & =\psi_{h t}\left(H_{t}^{c}+H_{t}^{h}\right) \\
A_{t}^{g} & =\psi_{a t}\left(A_{t}^{a b s, c}+A_{t}^{a b s, a}\right) \\
M_{t}^{g} & =\psi_{m t}\left(M_{t}^{m b s, c}+M_{t}^{m b s, h}\right) \\
B_{t}^{g} & =\psi_{b t}\left(B_{t}^{c}+B_{t}^{h}\right)
\end{aligned}
$$

We fix government consumption as an exogenous process $\bar{G}$ and impose lump-sum taxes to households $T_{t}$. Let $\bar{B}$ be the stock of long-term government debt fixed exogenously. The 
consolidated government budget constraint thus writes:

$$
\begin{aligned}
\bar{G}+\left(R_{b t}-1\right) \bar{B}=T_{t} & +\left(R_{s t}-R_{t}-\tau_{s}\right) Q_{t-1} S_{t-1}^{g}+\left(R_{h t}-R_{t}-\tau_{h}\right) q_{t-1}^{h} H_{t-1}^{g} \\
& +\left(R_{a t}-R_{t}-\tau_{a}\right) q_{t-1}^{a b s} A_{t-1}^{a b s, g}+\left(R_{m t}-R_{t}-\tau_{m}\right) q_{t-1}^{m b s} M_{t-1}^{g} \\
& +\left(R_{b t}-R_{t}-\tau_{b}\right) q_{t-1}^{b} B_{t-1}^{g}
\end{aligned}
$$

where QE policies are subject to efficiency $\operatorname{costs} \tau_{i}=0.001$ per unit of asset $i$ purchased.

\subsection{Market clearing and resource constraint}

The aggregate resource constraint is:

$$
Y_{t}=C_{t}+\left[1+f\left(\frac{I_{t}}{I_{t-1}}\right)\right] I_{t}+G+\Phi_{t}
$$

where $\Phi_{t}=\tau_{s} Q_{t} S_{t}^{g}+\tau_{h} q_{t}^{h} H_{t}^{g}+\tau_{a} q_{t}^{a b s} A_{t}^{g}+\tau_{m} q_{t}^{m b s} M_{t}^{g}+\tau_{b} q_{t}^{b} B_{t}^{g}$.

Equilibrium conditions on the markets for firm loans, ABS, mortgage loans, MBS, and longterm government bonds are:

$$
\begin{aligned}
K_{t+1} & =S_{t}^{c}+S_{t}^{a}+S_{t}^{h}+S_{t}^{g} \\
A_{t}^{a b s, a} & =A_{t}^{a b s, c}+A_{t}^{g} \\
H_{t} & =H_{t}^{c}+H_{t}^{h}+H_{t}^{g} \\
M_{t}^{m b s, h} & =M_{t}^{m b s, c}+M_{t}^{g} \\
B_{t} & =B_{t}^{c}+B_{t}^{h}+B_{t}^{g}
\end{aligned}
$$

Assuming a fixed and unit housing stock, the equilibrium on the housing market is:

$$
h_{t}=1
$$

Finally, the equilibrium on the labor market is given by:

$$
W_{t} \varrho_{t}=\chi L_{t}^{\varphi}
$$

The last market for short-term debt is cleared according to the Walras' law. 


\subsection{Yields to maturity}

The major goal of QE policies is to curb long-term interest rates. As in GKb, we build a simple term-structure to model yields to maturity of ten-year equivalent securities and bonds. Accordingly, the behavior of a ten-year corporate security rate is given by the sequence of nominal dividends net of depreciation for the first forty quarters. A principal payment equal to the steady state market price level of a security $\bar{Q}$ occurs the next quarter. Identically, the yield to maturity of a ten-year ABS has an equivalent payoff structure. Both nominal yields to maturity are given by:

$$
\begin{aligned}
P_{t} Q_{t} & =\mathbb{E}_{t} \sum_{s=1}^{40} \frac{\left(Z_{t+s}-\delta\right) P_{t+s}}{\left(1+i_{s t}\right)^{s}}+\frac{P_{t+40} \bar{Q}}{\left(1+i_{s t}\right)^{40}} \\
P_{t} q_{t}^{a b s} & =\mathbb{E}_{t} \sum_{s=1}^{40} \frac{\left(Z_{t+s}-\delta\right) P_{t+s}}{\left(1+i_{a t}\right)^{s}}+\frac{P_{t+40} q^{\bar{a} b s}}{\left(1+i_{a t}\right)^{40}}
\end{aligned}
$$

Further, we introduce a ten-year MBS rate that delivers a coupon payment $\Xi_{m}$ for the first forty quarters. At the date of maturity, the principal payment is the nominal steady-state price of the MBS $q^{\bar{m} b s}$, so that its ten-year nominal yield to maturity is:

$$
P_{t} q_{t}^{m b s}=\mathbb{E}_{t} \sum_{s=1}^{40} \frac{\Xi_{m} P_{t+s}}{\left(1+i_{m t}\right)^{s}}+\frac{P_{t+40} q^{\bar{m} b s}}{\left(1+i_{m t}\right)^{40}}
$$

We also consider a ten-year long-term government debt that pays a dollar for the first forty quarters. At the date of maturity, the bond repays its face value $\overline{q^{b}}$. Accordingly, the nominal yield to maturity of a ten-year government bond is:

$$
P_{t} q_{t}^{b}=\mathbb{E}_{t} \sum_{s=1}^{40} \frac{1}{\left(1+i_{b t}\right)^{s}}+\frac{\overline{q^{b}}}{\left(1+i_{b t}\right)^{40}}
$$

\section{Experiments}

\subsection{Model calibration}

We calibrate the model to the US economy. Time unit is the quarter. Our calibration is reported in Table 2 and follows GKb for many parameters.

In particular, as in $\mathrm{GKb}$, the subjective discount factor is $\beta=0.995$, the capital depreciation 
rate is $\delta=0.025$, the capital share in the production function is $\alpha=0.33$, and the elasticity of substitution among goods is $\varepsilon=4.167$. Further, the inverse of the Frisch labor supply elasticity is $\varphi=0.276$, the relative utility weight on labor is $\chi=3.41$ and the inverse elasticity of investment is $\eta_{i}=1.728$. We set the degree of habit in consumption to $h=0.815$. The price rigidity parameter is set to $\gamma^{p}=0.779$.

On the monetary side, the Taylor rule parameters are $\kappa_{\pi}=1.5$, and $\rho=0.8$. As in GKb, we use the markup variable as a proxy of the deviations of the output gap, associated to a coefficient $\kappa_{X}=-0.125$ in the Taylor rule.

We also follow GKb to calibrate the parameters related to commercial banks. The steady state spread between corporate securities return and the riskless rate $\left(\bar{R}_{s}-\bar{R}\right)$ is fixed at 100 basis points and the spread between long-term government bonds return and the riskless rate $\left(\bar{R}_{b}-\bar{R}\right)$ is set at 50 basis points. Households hold three-quarters of the quantity of long-term government debt $\bar{B}^{h}$ and half of the total of corporate securities, $\overline{S^{h}}$. We adjust the values of $\Delta, \theta_{c}$ and $\xi_{c}$ to hit the previous targets. The assets to equity ratio in commercial banks is fixed at $\phi^{c}=6$.

We rely on Meeks et al. (2014) to calibrate the parameters that pertain to SPEs..$^{4}$ Accordingly, the excess return on $\mathrm{ABS},\left(\bar{R}_{a}-\bar{R}\right)$ is 25 basis points. The assets to equity ratio is $\phi^{a}=7$. The relative divertibility of ABS is $\Theta=0.25$ and we fix the share of securitized loans $\frac{A^{a \bar{b} s, c}}{S^{c}}$ to $30 \%$ of the total of corporate securities held by commercial banks. We then adjust the values of $\theta_{a}$ and $\xi_{a}$ to hit the previous targets.

We use the estimates of Iacoviello \& Neri (2008) to calibrate the loan-to-value ratio $\mu$ and the weight on the housing stock in the utility function $j^{h}$. We set the curvature parameter on housing to $\zeta=3$. Based on FRED data from 1985 to $2007, \frac{\bar{H}}{\bar{Y}}$ is calibrated to match the mean ratio of home mortgages to real GDP. Using series on Agency and GSE backed mortgage pools and home mortgages, we fix the share of MBS. We find a quarterly mean ratio of $\frac{\bar{H}^{h}}{\bar{H}}=0.43$ over the period. The relative ratio of mortgage brokers assets to equity is trickier to calibrate. We consider a ratio $\phi^{h}=16$, which represents the mean fraction of debt securities to equity in GSEs in the sample. We use the primary mortgage market survey of the average spread between the 30-year fixed mortgage rate and the 10-year treasury rate provided by Freddie Mac to calibrate the excess return of mortgages $\left(R_{h}-R\right)$. This latter is set to 170 basis points. With this survey again, we fix our MBS spread using time series

\footnotetext{
${ }^{4}$ Meeks et al. (2014) design a "shadow banking" system in which shadow banks securitize corporate securities. Securitization vehicles are often cited to be principal actors of the shadow banking system. Thus, we assume that their mean calibration is consistent with our the calibration of our SPE sector.
} 
of 5/1-year adjustable rate mortgage and 10-year Treasury rate between 2005 and 2007. Thus, the MBS excess return $\left(R_{m}-R\right)$ is fixed to have a mean value of 115 basis points. The transfers to new mortgage brokers $\xi_{h}$, the divertability of assets $\theta_{h}$ and the relative divertibility of mortgage loans and MBS $\Phi$ and $\Xi$ are adjusted according to the previous targets.

Finally, the occupational survival probability is set to $\sigma=0.9716$. The ratio of the stock of long-term government bonds to output is 0.45 and the share of government spendings in GDP is $\frac{\bar{G}}{\bar{Y}}=0.2$. The households' portfolios transaction cost is $\kappa=1$. 
Table 2: Parameters values

\begin{tabular}{|c|c|}
\hline Capital share in the production function, $\alpha$ & 0.33 \\
\hline Discount rate factor, $\beta$ & 0.995 \\
\hline Capital depreciation rate, $\delta$ & 0.025 \\
\hline Habit parameter, $h$ & 0.815 \\
\hline Relative weight on labor, $\chi$ & 3.482 \\
\hline Inverse Frisch elasticity of labor supply, $\varphi$ & 0.276 \\
\hline Inverse elasticity of investment, $\eta_{i}$ & 1.728 \\
\hline Elasticity of substitution between goods, $\varepsilon$ & 4.167 \\
\hline Price rigidity parameter, $\gamma^{p}$ & 0.779 \\
\hline Taylor Rule inflation coefficient, $\kappa_{\pi}$ & 1.5 \\
\hline Taylor Rule markup coefficient, $\kappa_{X}$ & -0.125 \\
\hline Taylor Rule smoothing parameter, $\rho$ & 0.8 \\
\hline Survival probability, $\sigma$ & 0.9716 \\
\hline Divertibility of bankers assets, $\theta_{c}$ & 0.3451 \\
\hline Divertibility of loan brokers assets, $\theta_{a}$ & 0.2719 \\
\hline Divertibility of mortgage brokers assets, $\theta_{h}$ & 0.4146 \\
\hline Relative divertibility of government bonds, $\Delta$ & 0.5 \\
\hline Relative divertibility of ABS, $\Theta$ & 0.25 \\
\hline Relative divertibility of mortgage loans, $\Phi$ & 1.7 \\
\hline Relative divertibility of MBS, $\Xi$ & 1.15 \\
\hline Transfers to new bankers, $\xi_{c}$ & 0.001 \\
\hline Transfers to new loans brokers, $\xi_{a}$ & 0.001 \\
\hline Transfers to new mortgages brokers, $\xi_{h}$ & 0.001 \\
\hline Fraction of corporate securities in HH portfolios, $\frac{\overline{S^{h}}}{\bar{K}}$ & 0.5 \\
\hline Fraction of government bonds in HH portfolios, $\frac{\widehat{B h}}{\bar{B}}$ & 0.75 \\
\hline Treasury supply ratio, $\frac{\bar{B}}{\bar{Y}}$ & 0.45 \\
\hline Government expenditures ratio, $\frac{\bar{G}}{\bar{Y}}$ & 0.2 \\
\hline Portfolios adjustment costs, $\kappa$ & \\
\hline Loan-to-value ratio, $\mu$ & 0.85 \\
\hline Relative weight on housing, $j^{h}$ & 0.12 \\
\hline Elasticity of housing stock in the utility function, $\zeta$ & \\
\hline Ratio of ABS to the total of corporate securities, $\frac{A^{a \bar{b} s, c}}{\bar{S}^{c}}$ & 0.30 \\
\hline Ratio of mortgage debts to GDP, $\frac{\bar{H}}{\bar{Y}}$ & 0.35 \\
\hline Ratio of MBS to the total mortgage loans, $\frac{\bar{H}^{h}}{\bar{H}}$ & 0.43 \\
\hline
\end{tabular}

\subsection{Empirical versus theoretical IRFs}

We can now conduct various experiments. First, we confront the IRFs generated by the BVAR to those generated by the above DSGE. Second, we analyze the key differences in terms of IRFs between our model and the benchmark model of GKb. We argue that the 
differences characterize the portfolio rebalancing channel of QE policies while the common features portray the standard credit channel.

We now analyze the effects of a QE shock in our theoretical model and compare those to the empirical IRFs obtained in our BVAR analysis. We report the DSGE-generated IRFs for the $\log$ deviation of output $Y$, the inflation rate $\pi$, the corporate spread $\left(i_{s 10}-i_{i 10}\right)$, and the QE shock $\left(i_{i 10}-i\right)$. In the theoretical model, the QE shock is given by a long-term government bonds purchase program where the fraction of assets purchased is adjusted to match precisely the fall in the government spread that we have identified in the data. Accordingly, Figure 2 presents the IRFs of the experiment. Firstly, responses are fairly identical in terms of shapes and magnitude, except for real GDP, that does not show a negative deviation in the theoretical model. However, real GDP and inflation rate display hump-shaped and sizable positive responses in both models. This confirms the benefits of QE policies in terms of economic activity. We claim that the securization mechanisms introduced in the DSGE model are the source of the replicated portfolio rebalancing channel. As presented below, the dynamics of quantities and relative prices of different assets stress the role of imperfect arbitrage in the choices of investors among assets that are close substitutes. Accordingly, imperfect arbitrage explains the observed negative response of the theoretical and empirical corporate spreads (BAA-10Y, $i_{s 10}-i_{i 10}$ ), but it is also at the heart of the portfolio rebalancing channel, illustrated by the empirical response of the BAA-AAA spread. 
Figure 2: DSGE versus BVAR

(a) Output, $Y$

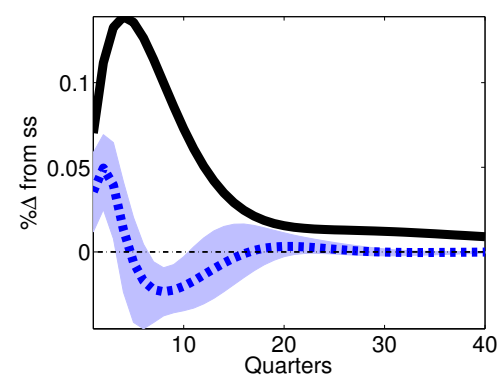

(b) Inflation Rate, $\pi$

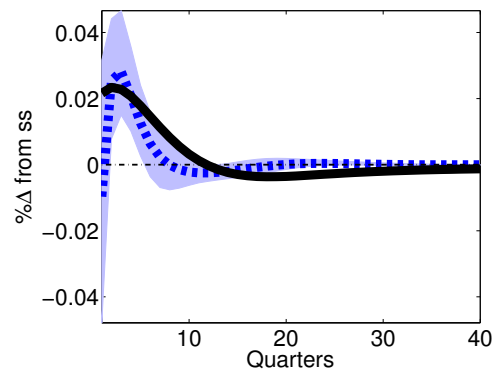

(c) BAA-AAA

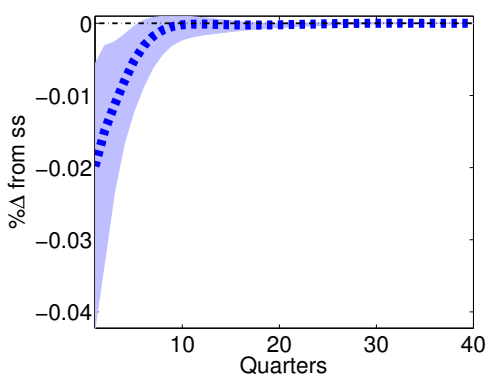

(d) BAA - 10Y, $\left(i_{s 10}-i_{i 10}\right)$

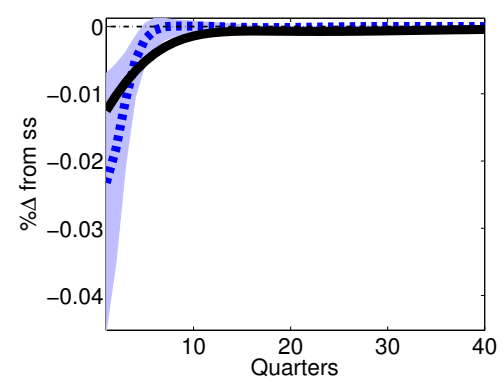

(e) 10Y-FFR, $\left(i_{i 10}-i\right)$

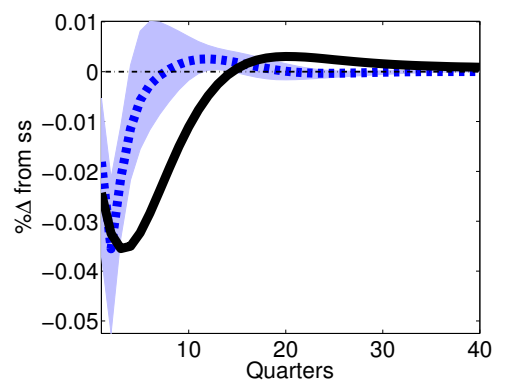

Black: DSGE model, Blue: BVAR model.

\subsection{Quantitative Easing policy}

We now compare the theoretical IRFs after a QE shock on corporate securities in our DSGE and in the baseline model of GKb. Both shocks are calibrated so that the total of purchases represent $1 \%$ of real output. We model a strong market segmentation, i.e. the absence of equity capital transfers among financial intermediaries to capture the kind of disruption of the financial intermediation the US experienced in 2008. Figures 3 and 4 present the simulations. Panel 1 shows that all asset spreads are significantly (mostly negatively) reacting to the purchase of firm securities (given by Equation (87)). The dynamics of relative asset prices, shown by the dynamics of spreads, generate large asset rebalancings that are the major effects of the program seen in Panel 2. From theses responses, we claim that we capture both the credit easing channel and the portfolio rebalancing channel of the purchase.

The credit easing channel works as in GKb. First, the central bank intermediation increases the demand for bonds and assets. With limits to arbitrage, households assets and bonds demands are quite inelastic in the short-run. In addition, the absence of financial frictions 
intermediation process of the central bank shifts the preferences of households to hold shortterm government debts instead of costly deposits in commercial banks. In other words, households arbitrage away the deadweight cost associated with the moral hazard problem that bankers face. Moreover, the presence of this balance sheet constraint further amplifies the effects of the purchase. Indeed, the issuance of firm loans must be exactly balanced by the multiple leverage ratios of equity capital stocks. All else being equal, the purchase of corporate securities will be then greater than banks holdings capacities. Given this shortrun relative inelasticity of total supply of bonds and assets, the QE shock directly pushes downward financial spreads. On one side, profits of commercial banks are partly protected by a net worth effect due to rises in asset prices. On the other side, they must offset asset market imbalances due to their restrictions to meet certain leverage ratios. As a result, they put pressure on financial spreads, which slightly impairs their balance sheets. Thus, they should engage in a reallocation of asset holdings. As in GKb, Equation (32) shows that frictions on long-term bonds are weaker than limits to arbitrage on corporate securities held by bankers. Thus, the yield of the former is a positive proportion $\Delta$ of the latter. That is why in GKb we observe a reallocation of bankers portfolios from corporate securities towards long-term government bonds holdings (which is not the case in our framewok). This sum of effects capture a financial accelerator mechanism on which the credit channel of QE transmission is based. Overall, the joint effects of limited expansion in bankers balance sheets and inelastic demand for assets and bonds leads to a disintermediation process. As a consequence, in terms of the funding of capital accumulation, firms rely more heavily on public intermediation and less on private intermediation.

Up to this point, we have neglected the housing market and the securitization mechanisms, and focused on the core dynamic of GKb. Let us now focus on the portfolio rebalancing channel and highlight the double-dip effects of QE policies. The latter can be described as follows. From the above analysis we know that deposits to commercial banks fall in response to a purchase of corporate securities, which triggers a reallocation among banks assets and bonds. With housing and securitization mechanisms, the adjustment process is more complex. As a matter of fact, we observe a rise in the holdings of mortgage loans $H^{c}$ in bankers portfolios. This is due to the presence of frictions in the housing market: limits to arbitrage seen in Equation (66) suggest that an increase in the market value of the mortgage asset $q^{h}$ gives the opportunity to benefit from higher earnings through the detention of further mortgage loans. Accordingly, the net demand for mortgage loans increases with the fall in the spread $\left(\mathbb{E}\left(R_{h}\right)-\mathbb{E}\left(R_{s}\right)\right)$, within the bounds of the fixed housing stock. Interestingly, equations 27) and (28) show that bankers do not rebalance portfolios away from firm loans 
to mortgage loans $H^{c}$ but rather lower their holdings of ABS, $A^{a b s, c}$, MBS, $M^{m b s, c}$, and long-term government bonds, $B^{c}$. Overall, market imbalances, the shortage of deposits and constraints on leverage ratios, all lead bankers to reduce their ability to pool firm loans $S^{a}$ and mortgage loans $H^{h}$. In addition, equations (47) and 63) show that ABS and MBS are positively correlated respectively to the holdings of pool of corporate securities and pool of mortgages. Thus, the binding constraints of SPEs and GSEs trigger a reduction of securitization activities that results in a fall of the supply of $\operatorname{ABS}\left(A^{a b s, a}\right)$ and of $\mathrm{MBS}$ $\left(M^{m b s, h}\right)$. Again, equity capital stocks of these intermediaries $N^{a}$ and $N^{h}$ are somehow sustained by net worth effects due to the observed increase in asset prices.

Concerning yields to maturity, Figure 3 (Panel 1) reports the relationship between financial spreads and the drop in long-term yields. As in GKb, we provide a ten-year "risk-free" swap rate $i_{i 10}$ based on the rate of a bond that would pay the nominal interest rate each quarter for ten years. In the credit channel of $\mathrm{QE}$ transmission, $i_{s 10}$ is the key variable of interest as it drives the dynamics of investment expenditures. Equations (31) and (32) indicate that $R_{a}$ and $R_{b}$ deviate in the short-run by $\Theta$ and $\Delta$ times less than $R_{s}$, respectively in response to a $\mathrm{QE}$ shock. However, we observe that the magnitude of the respective declines in $i_{s 10}$ and $i_{b 10}$ are different and greater than the portion $\Delta$ in the long-run (a fact that can also be seen through the dynamics of spreads, $i_{s 10}-i_{i 10}, i_{b 10}-i_{i 10}$ and $i_{s 10}-i_{b 10}$. Following a similar pattern, the short-term proportion $\Theta$ betwen $i_{a 10}$ and $i_{s 10}$ (seen in Equation (31) ) slightly increases over time. This assessment is also noticeable in the drops of $i_{s 10}-i_{i 10}$, $i_{a 10}-i_{i 10}$ and $i_{s 10}-i_{a 10}$. Moreover, the weight $\Xi$ between $R_{m}$ and $R_{s}$ shown in Equation (30) is also increasing after a QE shock on corporate securities. Actually, $i_{m 10}$ drops by more than two times the decrease in $i_{s 10}$, which is also visible in the spreads $i_{m 10}-i_{i 10}$, $i_{s 10}-i_{i 10}$ and $i_{m 10}-i_{s 10}$. In other words, the level of $i_{s 10}$ is deviating from the level of $i_{m 10}$, which we take as evidence of a portfolio rebalancing channel. This latter alters the shape of the respective yield curves of these different assets. This channel complements the credit channel that makes all spreads fall similarly, i.e. that shifts the yield curve downward while preserving its shape.

Finally, our QE shock is transmitted to the real activity with sizable differences in terms of deviations of macroeconomic variables from their initial values. In particular, capital accumulation and output show larger responses. This phenomenon is mostly demand-driven and is amplified by the two channels analyzed above. Indeed, a big part of the difference between both models is due to a greater drop in the cost of capital $R_{s}$, which in turn, leads entrepreneurs to raise investment in physical capital. As a result, investment expenditures and households consumption rise, so that output is further stimulated with positive feedback 
effects on aggregate demand.

Figure 3: DSGE versus GKb, purchase of firm securities, Panel 1

(a) $Q$

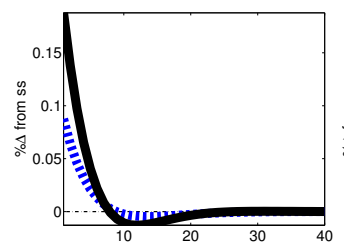

(f) $R$

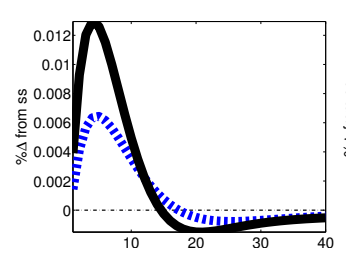

(k) $\mathbb{E}\left(R_{m}\right)-\mathbb{E}\left(R_{s}\right)$

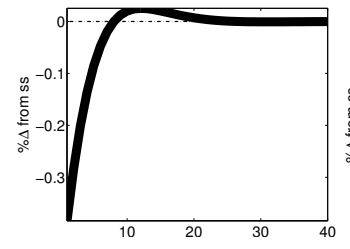

(p) $i_{a 10}-i_{i 10}$

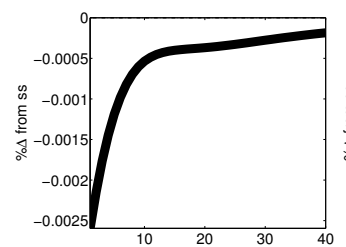

(b) $q^{b}$

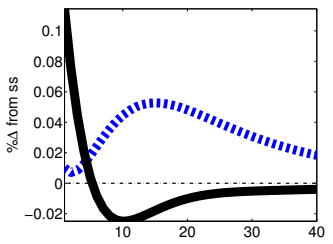

(g) $\mathbb{E}\left(R_{s}\right)-R$

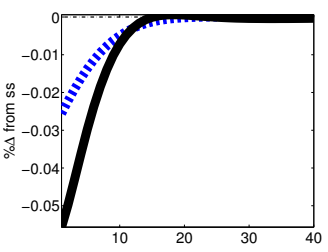

(l) $i_{s 10}-i_{i 10}$

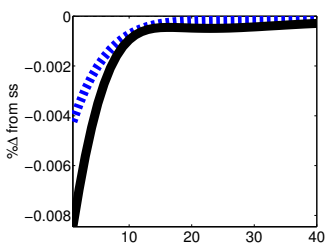

(q) $i_{m 10}-i_{s 10}$

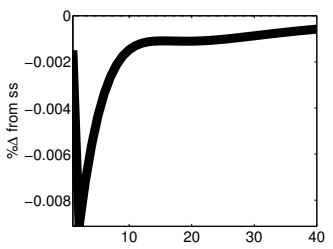

(c) $q^{h}$

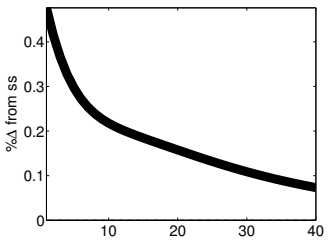

(h) $\mathbb{E}\left(R_{s}\right)-\mathbb{E}\left(R_{b}\right)$

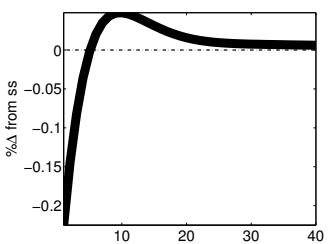

(m) $i_{b 10}-i_{i 10}$

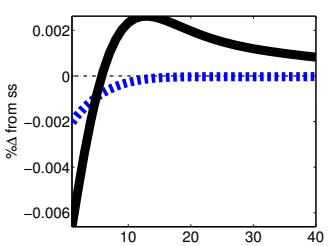

(r) $i_{m 10}-i_{i 10}$

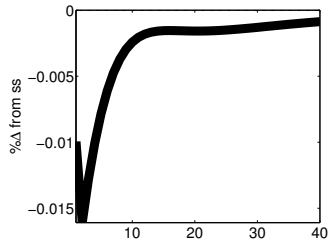

(d) $q^{a b s}$

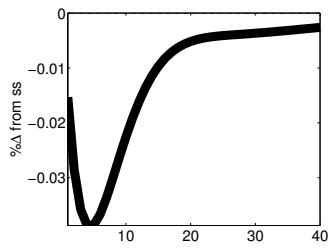

(i) $\mathbb{E}\left(R_{s}\right)-\mathbb{E}\left(R_{a}\right)$

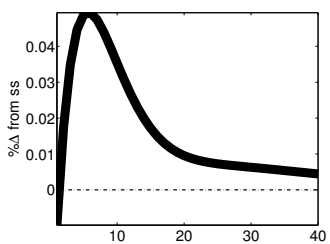

(n) $i_{s 10}-i_{b 10}$

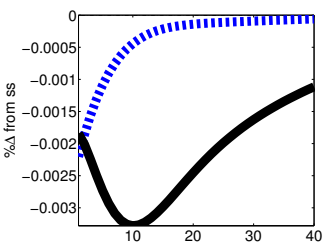

(s) $i_{s 10}$

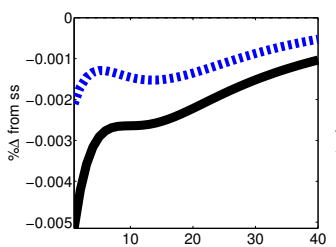

(v) $i_{m 10}$
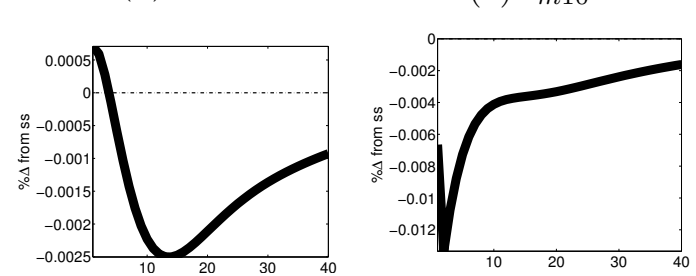

Black: our DSGE, Blue: model of GKb.

(u) $i_{a 10}$ (e) $q^{m b s}$

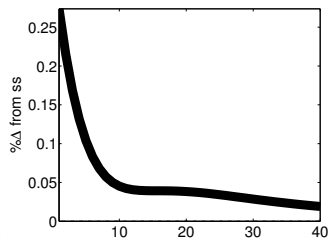

(j) $\mathbb{E}\left(R_{h}\right)-\mathbb{E}\left(R_{s}\right)$

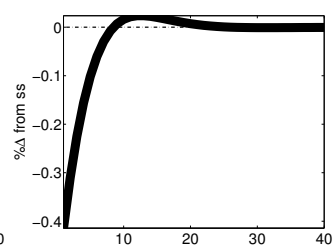

(o) $i_{s 10}-i_{a 10}$

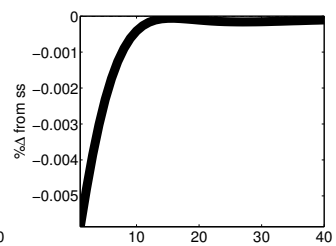

(t) $i_{b 10}$

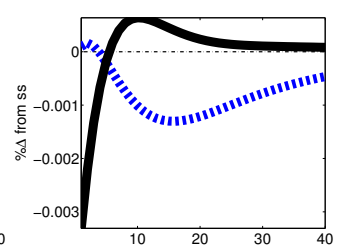


Figure 4: DSGE versus GKb, purchase of firm securities, Panel 2

(a) $\frac{S^{g}}{Y}$

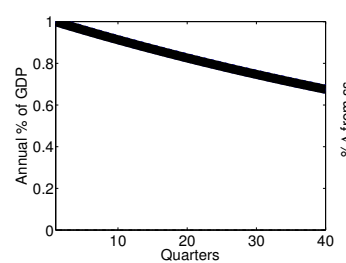

(f) $S^{h}$

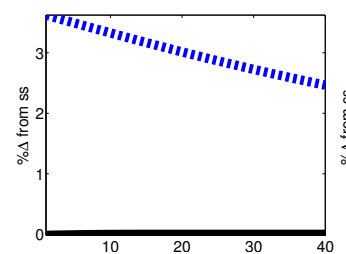

(k) $S^{c}$

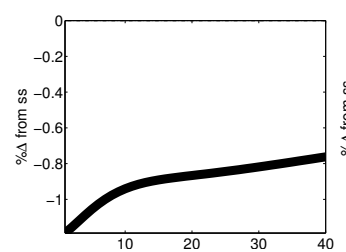

(p) $N^{c}$

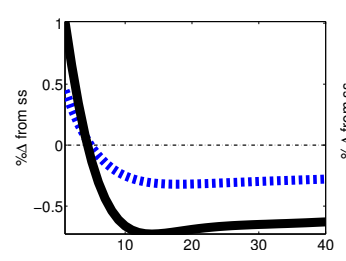

(u) $\phi^{a}$

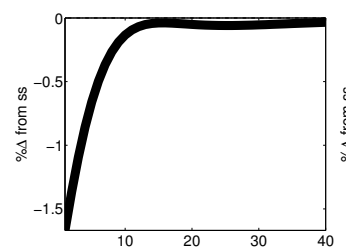

(b) $K$

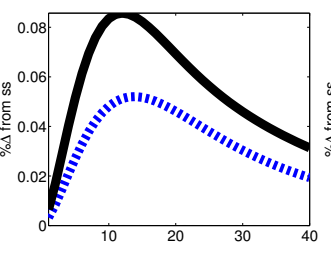

(g) $B^{h}$

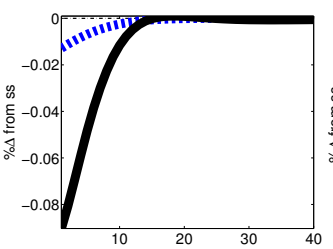

(l) $B^{c}$

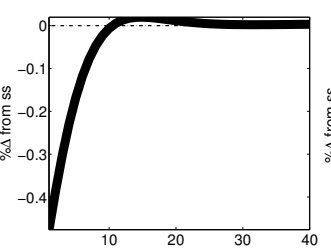

(q) $\phi^{c}$

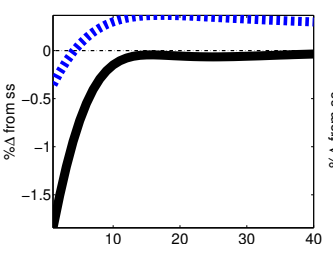

(v) $H^{h}$

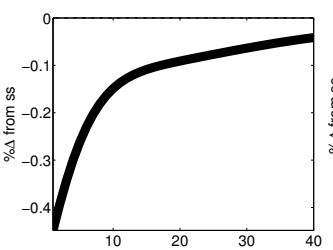

(c) $Y$

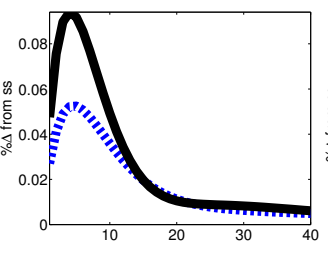

(h) $D$

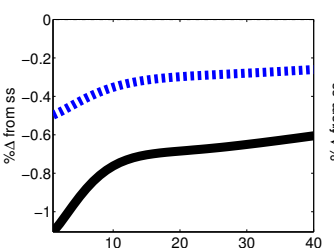

(m) $H^{c}$

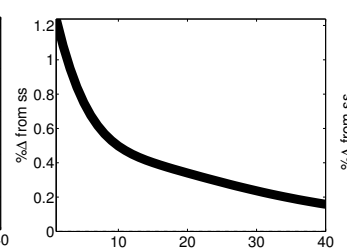

(r) $S^{a}$

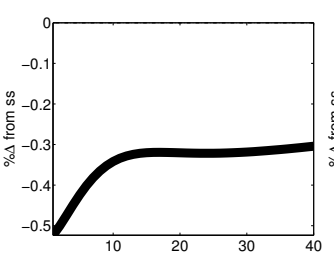

(w) $M^{m b s, h}$

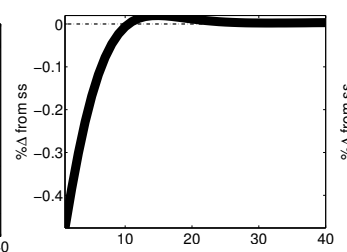

(d) $I$

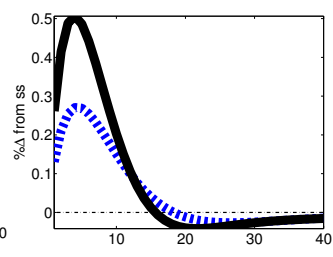

(i) $D^{g}$

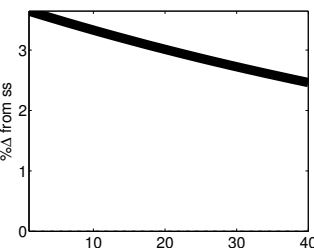

(n) $A^{a b s, c}$

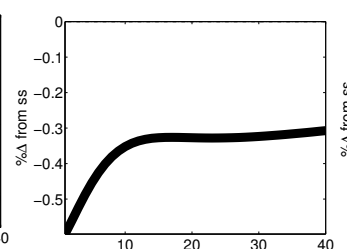

(s) $A^{a b s, a}$

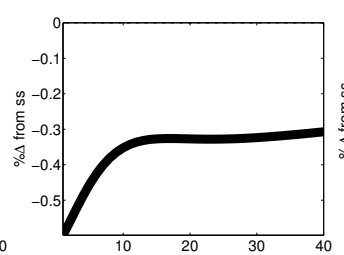

(x) $N^{h}$

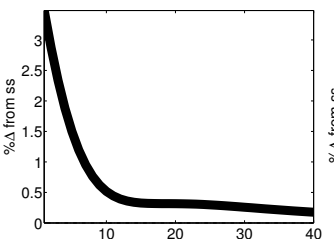

(e) $C$

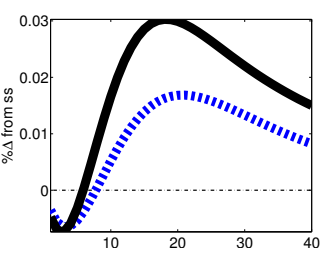

(j) $H$

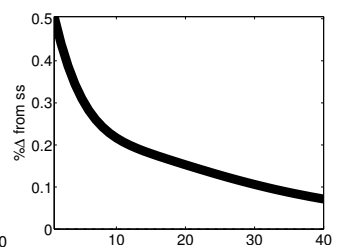

(o) $M^{m b s, c}$

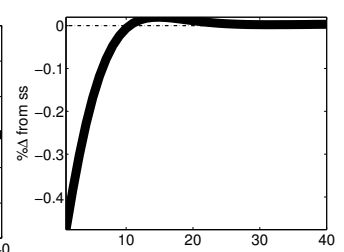

(t) $N^{a}$

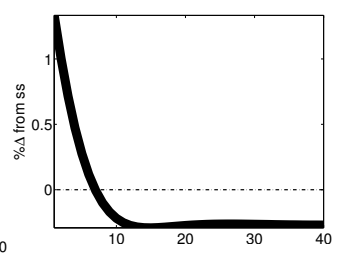

(y) $\phi^{h}$

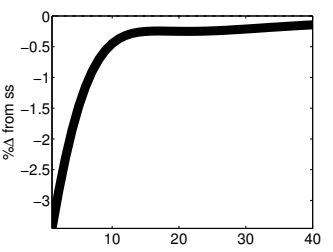

Black: our DSGE, Blue: model of GKb. 


\section{Conclusion}

This paper provides a dual approch using empirical and theoretical models to capture the portfolio rebalancing channel of QE. The BVAR model is able to show that an identified purchase of long-term government bonds not only affects its yields but also those of close substitutes (here high-quality corporate bonds). We then built a calibrated DSGE model with financial frictions to disentangle the core mechanism behind the portfolio rebalancing channel of QE. Fed with an exogenous QE shock on long-term government bond, we compare the IRFs of the theoretical model to those obtained with the BVAR model. We find a satisfying match among the results which allows us to claim that the securitization mechanisms in the DSGE model are the linchpin of a replicated portfolio rebalancing channel. In addition, we report and compare the IRFs of GKb to our responses. We argue that any difference between both models is due to the portfolio rebalancing channel. Overall, the presence of securitization mechanisms and strong market segmentation enhance the effects of a QE shock to the economy and alter the shapes of our designed yield curves of different assets and bonds. Nevertheless, we believe this framework is far too simple to entirely explain recent events providing motivations for further research, which should incorporate modifications of the DSGE model to loosen the market segmentation and explore the impacts of different exit strategies on the whole dynamic.

\section{Acknowledgements}

I gratefully acknowledge Aurélien Eyquem for helpful comments and suggestions. I also thank Andrew Binning, Peter Karadi and Roland Meeks for their help and computational support. 


\section{References}

Binning, A. (2013), Underidentified SVAR models: A framework for combining short and long-run restrictions with sign-restrictions, Working Paper 2013/14, Norges Bank.

Calvo, G. A. (1983), 'Staggered prices in a utility-maximizing framework', Journal of Monetary Economics 12(3), 383-398.

Canova, F. (2007), Methods for Applied Macroeconomic Research, Princeton University Press.

Cúrdia, V., Ferrero, A. \& Chen, H. (2012), The Macroeconomic Effects of Large-Scale Asset Purchase Programs, 2012 Meeting Papers 372, Society for Economic Dynamics.

Cúrdia, V. \& Woodford, M. (2011), 'The central-bank balance sheet as an instrument of monetarypolicy', Journal of Monetary Economics 58(1), 54-79.

Dai, M., Dufourt, F. \& Zhang, Q. (2013), Large Scale Asset Purchases with Segmented Mortgage and Corporate Loan Markets, Working Papers halshs-00842279, HAL.

D’Amico, S., English, W. B., López-Salido, D. \& Nelson, E. (2012), The Federal Reserve's large-scale asset purchase programs: rationale and effects, Finance and Economics Discussion Series 2012-85, Board of Governors of the Federal Reserve System (U.S.).

Doan, T., Litterman, R. B. \& Sims, C. A. (1983), Forecasting and Conditional Projection Using Realistic Prior Distributions, NBER Working Papers 1202, National Bureau of Economic Research, Inc.

Engen, E. M., Laubach, T. \& Reifschneider, D. L. (2015), The Macroeconomic Effects of the Federal Reserve's Unconventional Monetary Policies, Finance and Economics Discussion Series 2015-5, Board of Governors of the Federal Reserve System (U.S.).

Falagiarda, M. (2013), Evaluating Quantitative Easing: A DSGE Approach, MPRA Paper 49457, University Library of Munich, Germany.

Foerster, A. T. (2015), 'Financial crises, unconventional monetary policy exit strategies, and agents' expectations', Journal of Monetary Economics 76(C), 191-207.

Gagnon, J., Raskin, M., Remache, J. \& Sack, B. (2011), 'The Financial Market Effects of the Federal Reserve's Large-Scale Asset Purchases', International Journal of Central Banking $7(1), 3-43$. 
Gertler, M. \& Karadi, P. (2011), 'A model of unconventional monetary policy', Journal of Monetary Economics 58(1), 17-34.

Gertler, M. \& Karadi, P. (2013), 'QE 1 vs. 2 vs. 3. . . : A Framework for Analyzing Large-Scale Asset Purchases as a Monetary Policy Tool', International Journal of Central Banking 9(1), 5-53.

Guerrieri, L. \& Iacoviello, M. (2015), 'OccBin: A toolkit for solving dynamic models with occasionally binding constraints easily', Journal of Monetary Economics 70(C), 22-38.

Harrison, R. (2012), Asset purchase policy at the effective lower bound for interest rates, Bank of England working papers 444, Bank of England.

Hilberg, B. \& Hollmayr, J. (2013), Asset prices, collateral, and unconventional monetary policy in a DSGE model, Discussion Papers 36/2013, Deutsche Bundesbank, Research Centre.

Iacoviello, M. (2005), 'House Prices, Borrowing Constraints, and Monetary Policy in the Business Cycle', American Economic Review 95(3), 739-764.

Iacoviello, M. \& Neri, S. (2008), Housing market spillovers: Evidence from an estimated DSGE model, Temi di discussione (Economic working papers) 659, Bank of Italy, Economic Research and International Relations Area.

Joyce, M., Liu, Z. \& Tonks, I. (2014), Institutional investor portfolio allocation, quantitative easing and the global financial crisis, Bank of England working papers 510, Bank of England.

Litterman, R. B. (1985), Forecasting with Bayesian vector autoregressions five years of experience, Working Papers 274, Federal Reserve Bank of Minneapolis.

Meeks, R., Nelson, B. \& Alessandri, P. (2014), Shadow banks and macroeconomic instability, Bank of England working papers 487, Bank of England.

Meyer-Gohde, A. (2010), 'Matlab code for one-sided HP-filters', QM\&RBC Codes, Quantitative Macroeconomics \& Real Business Cycles.

URL: https://ideas.repec.org/c/dge/qmrbcd/181.html

Peersman, G. (2011), Macroeconomic Effects of Unconventional Monetary Policy in the Euro Area, CESifo Working Paper Series 3589, CESifo Group Munich. 
Rubio-Ramírez, J. F., Waggoner, D. F. \& Zha, T. (2010), 'Structural Vector Autoregressions: Theory of Identification and Algorithms for Inference', Review of Economic Studies 77(2), 665-696.

Verona, F., Martins, M. M. F. \& Drumond, I. (2013), (Un)anticipated monetary policy in a DSGE model with a shadow banking system, Research Discussion Papers 4/2013, Bank of Finland.

Wen, Y. (2014), 'When and how to exit quantitative easing?', Federal Reserve Bank of St. Louis Review 96(3), 243-265.

Woodford, M. (2012), 'Methods of policy accommodation at the interest-rate lower bound', Proceedings - Economic Policy Symposium - Jackson Hole pp. 185-288. 